\title{
Growth of oxide-mediated ternary silicide controlled by a Si cap layer by rapid thermal annealing
}

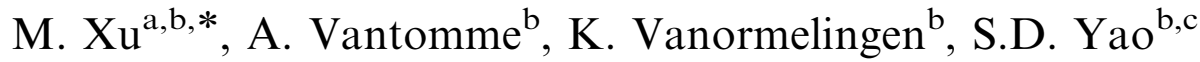 \\ ${ }^{a}$ Laboratory for Low-dimensional Structure Physics, Institute of Solid State Physics, Sichuan Normal University, Chengdu 610068, PR China \\ ${ }^{\mathrm{b}}$ Instituut voor Kern-en Stralingsfysica, Katholieke Universiteit Leuven, Celestijnenlaan 200 D, B-3001 Leuven, Belgium \\ ${ }^{\mathrm{c}}$ School of Physics, Beijing University, Beijing 100871, PR China
}

Received 27 March 2007; received in revised form 26 June 2007; accepted 3 July 2007

Available online 7 July 2007

\begin{abstract}
We reported a simple method to grow good-quality $\mathrm{CoSi}_{2}$ film by using $\mathrm{Si}$ cap technology and introducing moderate Ni. First, a cobalt layer of $\sim 15 \mathrm{~nm}$ with a Si cap layer with a different thickness deposited onto the Si surface with a thin silicon oxide buffer is applied to investigate the formation of $\mathrm{CoSi}_{2}$ by ex situ rapid thermal annealing. It was found that a 13 nm thick Si cap layer could significantly improve the crystal quality of oxide-mediated $\mathrm{CoSi}_{2}$ film. Setting the $\mathrm{Si}$ cap thickness at $13 \mathrm{~nm}$, we revealed that introduction of Ni can further improve the crystal quality of the silicide film in comparison to the pure Co silicide, and a ratio of Ni to Co at round 1:8 causes the lowest sheet resistance, $\sim 5 \Omega /$ sq.
\end{abstract}

(C) 2007 Elsevier B.V. All rights reserved.

PACS: 61.10.Nz; 68.35.-p; 68.37.-d

Keywords: Silicide film; Si cap layer; Rapid thermal annealing

\section{Introduction}

In the past 20 years, the study on the epitaxial metal silicides has received much interest due to their applications in very large-scale integration technology. Among the silicide materials, the $\mathrm{CoSi}_{2}$ has been considered to be one of the most attractive materials for contact and interconnect in the next generation devices because of its low resistance, high-thermal stability and process compatibilities [1]. Generally, the small lattice mismatch with $\mathrm{Si}$ is expected to grow a good epitaxial $\mathrm{CoSi}_{2}$. Indeed, this has been demonstrated by using template [2] or oxide-mediated epitaxy technology [3] in the case of very thin $\mathrm{CoSi}_{2}$ film. For the thicker $\mathrm{CoSi}_{2}$ film, i.e., cobalt thickness $>10 \mathrm{~nm}$, one has to apply $\mathrm{Ti}$ buffer [4] or repeated growth technology [3]. However, the silicides suffer from the generation of large voids in the epitaxial $\mathrm{CoSi}_{2}$ layers near

\footnotetext{
*Corresponding author. Institute of Solid State Physics, Sichuan Normal University, Chengdu 610068, PR China.

E-mail address: hsuming_2001@yahoo.com.cn (M. Xu).
}

the edges of field oxide and an inability to grow uniform epitaxial $\mathrm{CoSi}_{2}$ layers with thickness of less than $40 \mathrm{~nm}$. Alternatively, epitaxial $\mathrm{CoSi}_{2}$ can be fabricated by mesotaxy, using high-energy, high-dose, Co implantations $[5,6]$, but these techniques require dedicated tools not commonly available in modern $\mathrm{Si}$ processing facilities. To solve these problems, the ternary epitaxial silicides $\left(\mathrm{Co}_{x} \mathrm{Ni}_{1-x} \mathrm{Si}_{2}\right)$ may prove to be a better choice than pure $\mathrm{CoSi}_{2}$ due to the smaller lattice mismatch of $\mathrm{NiSi}_{2}$ compared to $\mathrm{Si}$ substrate. Especially, the bulk material of the ternary silicides $\left(\mathrm{Co}_{x} \mathrm{Ni}_{1-x} \mathrm{Si}_{2}, 0.5<x<1\right)$ has electrical resistance nearly identical to that of $\mathrm{CoSi}_{2}$ [7]. The smaller lattice mismatch of $\mathrm{Co}_{x} \mathrm{Ni}_{1-x} \mathrm{Si}_{2}$ to $\mathrm{Si}$ compared to $\mathrm{CoSi}_{2}$ has proved to successfully grow thin single crystal $\mathrm{Co}_{x} \mathrm{Ni}_{1-x} \mathrm{Si}_{2}$ layers on $\mathrm{Si}\left(\begin{array}{lll}1 & 1 & 1\end{array}\right)$ [7]. In this paper, we explored a simple method to grow good-quality $\mathrm{CoSi}_{2}$ by using $\mathrm{Si}$ cap technology and introducing moderate $\mathrm{Ni}$. We first revealed that there exists an optimal $\mathrm{Si}$ cap thickness to grow oxide-mediated $\mathrm{CoSi}_{2}$ on $\mathrm{Si}(001)$, i.e., a $13 \mathrm{~nm}$ thick $\mathrm{Si}$ cap layer can achieve the best crystal quality of oxide-mediated $\mathrm{CoSi}_{2}$ on $\mathrm{Si}\left(\begin{array}{lll}0 & 0 & 1\end{array}\right)$ by assuming a $15 \mathrm{~nm}$ Co layer and by rapid thermal annealing 
(RTA) in the $\mathrm{N}_{2}$ ambient. Furthermore, we showed that the introduction of moderate $\mathrm{Ni}$ does not only improve the crystal quality of $\mathrm{Co}_{x} \mathrm{Ni}_{1-x} \mathrm{Si}_{2}$, but also decreases the sheet resistance.

\section{Experimental}

P-type $\operatorname{Si}(100)$ substrates were used in this study. Substrates were cleaned chemically and dipped in a dilute $\mathrm{HF}$ solution to remove the native oxide. A thin $\mathrm{SiO}_{x}$ layer was then grown by submerging the substrates in a hot $\mathrm{NH}_{4} \mathrm{OH}: \mathrm{H}_{2} \mathrm{O}_{2}: \mathrm{H}_{2} \mathrm{O}=1: 1: 4$ solution for $25 \mathrm{~min}$ (ammoniacal oxide). Substrates were then loaded in an UHV evaporation system. Co was evaporated at rate typically, $0.015 \mathrm{~nm} / \mathrm{s}$ and $\mathrm{Ni}$ was grown at rates $0-0.015 \mathrm{~nm} / \mathrm{s}$. Subsequently, a $\mathrm{Si}$ cap layer with the thickness of 0-30 nm was deposited in the same UHV system in order to improve the quality of silicide film. Rapid thermal annealing from 550 to $1050^{\circ} \mathrm{C}$ was performed to study the formation of $\mathrm{Co}_{x} \mathrm{Ni}_{1-x} \mathrm{Si}_{2}$. Before reaching the higher annealing temperature, each sample is first heated and kept at $300{ }^{\circ} \mathrm{C}$ for $15 \mathrm{~s}$ in order to achieve a uniform mixture of $\mathrm{Co}, \mathrm{Ni}$ and $\mathrm{Si}$.

The film structure was characterized by X-ray diffraction (XRD) and Rutherford backscattering (RBS). $\mathrm{Cu} \mathrm{K} \alpha$ radiation is used for the XRD measurements. High-angle diffraction was carried out from $27^{\circ}$ to $75^{\circ}$ with a step size $0.01^{\circ}$. Rutherford backscattering spectroscopy (RBS)/ channeling experiment was carried out using a $1.57 \mathrm{MeV}$ $\mathrm{He}^{+}$ion beam.

\section{Results and discussion}

First, we investigated the effect of an amorphous Si cap layer with a different thickness on the formation of $\mathrm{CoSi}_{2}$ by depositing a cobalt layer of $\sim 15 \mathrm{~nm}$ onto the $\operatorname{Si}\left(\begin{array}{lll}0 & 0 & 1\end{array}\right)$ covered with a thin silicon oxide layer and following ex situ rapid thermal annealing. From the high-angle X-ray diffraction (HAXRD) of the films annealed up to $1050{ }^{\circ} \mathrm{C}$, no $\mathrm{CoSi}_{2}$ (111) or (220) diffraction peak is observed except $\mathrm{CoSi}_{2}(400)$ diffraction peak. Fig. 1 shows HAXRD of the Co disilicide film around (400) diffraction peak after annealing at $1050{ }^{\circ} \mathrm{C}$. To obtain obvious $\mathrm{CoSi}_{2}$ (4 00$)$ peak, $(\theta+\delta)-2 \theta$ scan was applied, where $\delta$ is a small constant angle. One can see that the $\mathrm{CoSi}_{2} \quad(400)$ diffraction peak appears only when the thickness of $\mathrm{Si}$ cap layer is not too thick, i.e., $150 \AA$ or thinner. It should be pointed out that, for the sample without a $\mathrm{Si}$ cap layer, $\mathrm{CoSi}_{2}(400)$ diffraction peak disappears as the temperature is increased up to $1050{ }^{\circ} \mathrm{C}$ and in the sample with a $\mathrm{Si}$ cap layer up to $30 \mathrm{~nm}$, no $\mathrm{CoSi}_{2}$ (400) diffraction peak is observed after annealing from 550 to $1050^{\circ} \mathrm{C}$. Moreover, seen from Fig. 1, the $\mathrm{CoSi}_{2}(400)$ peak position shifts from $70.5^{\circ}$ to $70.85^{\circ}$ when the cap layer thickness increases from 0 to $13 \mathrm{~nm}$; as the cap layer is $15 \mathrm{~nm}$, the $\mathrm{CoSi}_{2}(400)$ peak slightly shifts back to the lower angle. The diffraction peaks correspond to a perpendicular strain from a

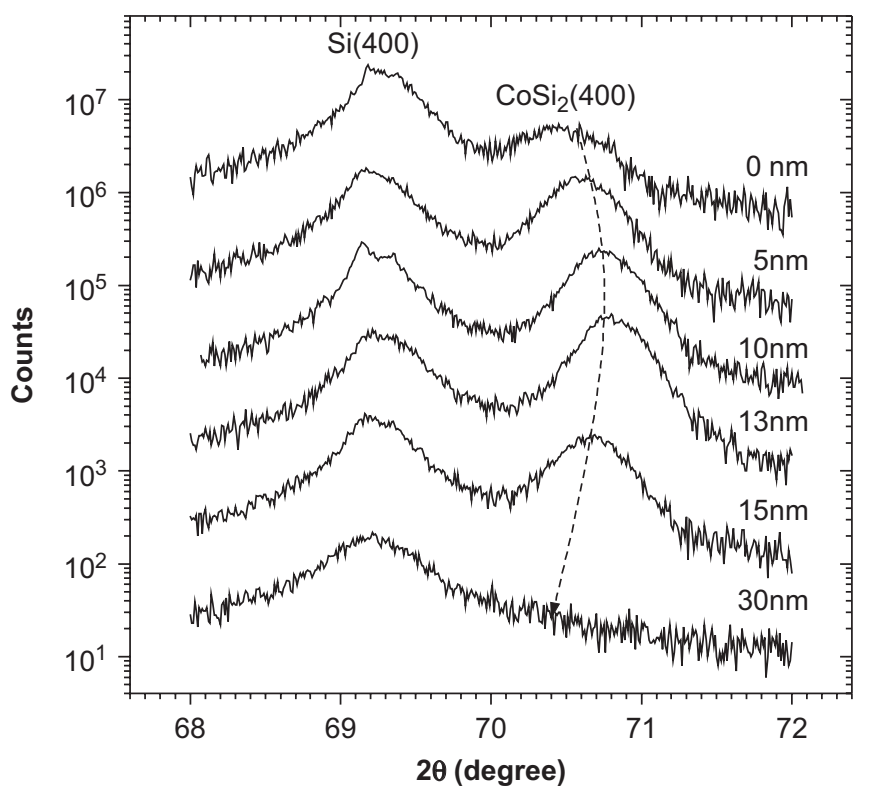

b

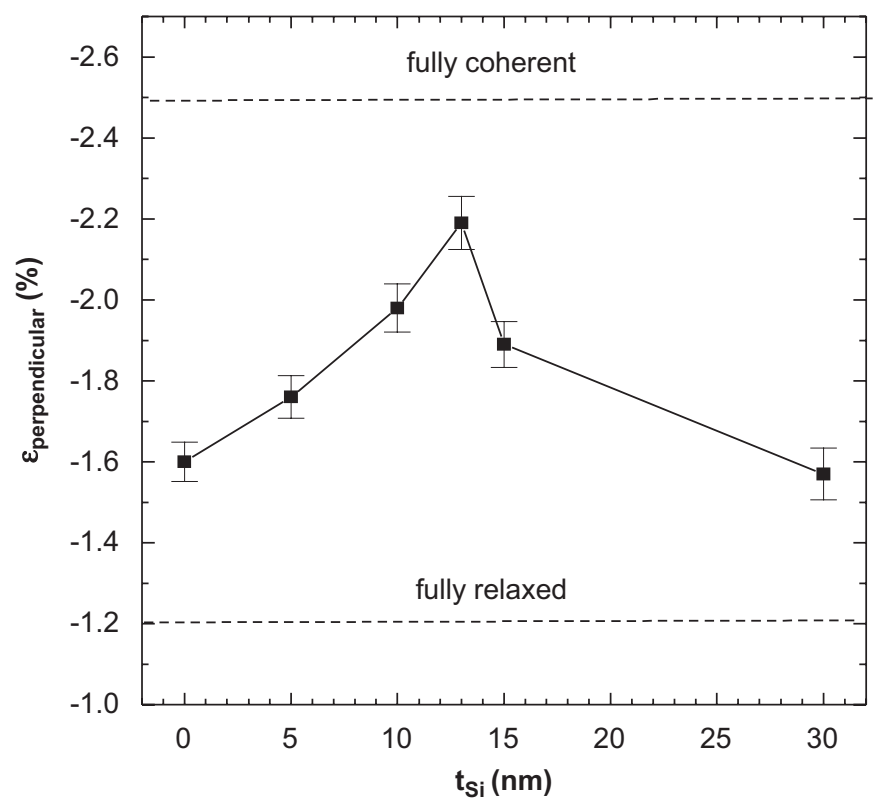

Fig. 1. (a) High-angle X-ray diffraction (HAXRD) spectrum of the oxidemediated $\mathrm{CoSi}_{2}$ films on $\mathrm{Si}(100)$ with different $\mathrm{Si}$ cap layer thickness, 0-30 nm from the up curve to the down one after annealing at $1050^{\circ} \mathrm{C}$. (b) Variation of the perpendicular strain of $\mathrm{CoSi}_{2}$ film formed by RTA at $1050^{\circ} \mathrm{C}$ with a different $\mathrm{Si}$ cap layer thickness.

$\varepsilon^{\perp}=-1.60 \%$ to $-2.19 \%$, indicating that the $\mathrm{CoSi}_{2}$ becomes more coherent as the $\mathrm{Si}$ cap layer is increased up to $13 \mathrm{~nm}$. When the anneal temperature was reduced to $700{ }^{\circ} \mathrm{C}$, the $\mathrm{CoSi}_{2}(400)$ diffraction peak was observed only for capping layers of 10 and $13 \mathrm{~nm}$. This further evidences that too thin or thick Si cap impedes the formation of $\mathrm{Co}$ disilicide.

The crystalline quality of the silicide film has been checked by measuring the RBS/channeling spectra. The polycrystalline Co silicide is determined for all the samples, 
but a minimum value of $\chi_{\min }$ occurs in the case with $13 \mathrm{~nm}$ cap layer when the anneal temperature is up to $1050{ }^{\circ} \mathrm{C}$. The minimum value of $\chi_{\min } \sim 29 \%$ is obtained, which is a bit higher than that of Co disilicide formed by reaction deposition epitaxy (RDE) [8,9] or with $\mathrm{Ti}$ interlayer [4].

Fig. 2 displays the random RBS spectrum of Co silicide with a different $\mathrm{Si}$ cap thickness. It is interesting to note that, without cap layer, the silicidation of Co atoms is obviously companied by a tail on the low-energy side. As the Si cap layer thickness increases, the Co peak narrows, indicating that silicidation becomes more difficult. When the thickness of Si cap layer is above $13 \mathrm{~nm}$, the Co peak is almost the same. As is known, the Ti interlayer acts as a diffusive barrier, which retards the formation of $\mathrm{CoSi}_{2}$ up to a higher temperature. In our experiment, $\mathrm{Si}$ cap layer acts similarly to the $\mathrm{Ti}$ interlayer, the existence of which slows the silicidation process or raises the formation temperature of $\mathrm{CoSi}_{2}$. It was found that the $\mathrm{Si}$ cap layer of a certain thickness not only improved the quality of the $\mathrm{CoSi}_{2}$ but also decreased the formation temperature of $\mathrm{CoSi}_{2}$. Since $\mathrm{Si}$ is one of the reactive elements for $\mathrm{CoSi}_{2}$, the existence of amorphous $\mathrm{Si}$ cap layer should be able to further induce the silcidation. The opposite is true as the amorphous $\mathrm{Si}$ cap layer slows the diffusion. This is because, as a new $\mathrm{Si}$ source, the amorphous $\mathrm{Si}$ cap layer slows the diffusion rate of Co atoms into the $\mathrm{Si}$ substrate by first forming $\mathrm{Co}_{2} \mathrm{Si}$ or $\mathrm{CoSi}$ due to the lower heat of formation between $\mathrm{Co}$ atoms and amorphous $\mathrm{Si}$.

In order to check the detailed formation of oxide-mediated $\mathrm{CoSi}_{2}$ with a Si cap layer, we performed the measurement and simulation of X-ray reflectivity. As is well known, X-ray specular reflection is very sensitive to the distribution of

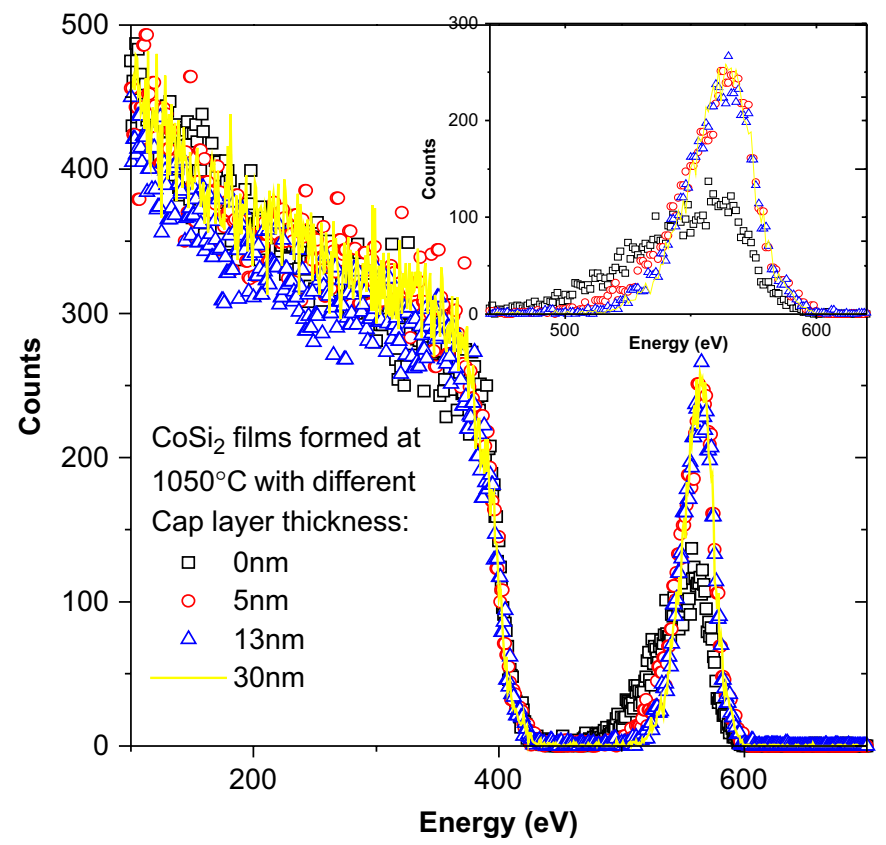

Fig. 2. $1.57 \mathrm{MeV}^{4} \mathrm{He}$ backscattering spectra of the oxide-mediated $\mathrm{CoSi}_{2}$ films on $\mathrm{Si}(100)$ with a different $\mathrm{Si}$ cap layer thickness after annealing at $1050^{\circ} \mathrm{C}$. The scattering angle is $170^{\circ}$. electrons at the heterointerface. By theoretically fitting the measured specular reflectivity curve at grazing angle condition, we are able to extract the electron density profile across the heterointerface. In other words, the information on the atomic density and thickness of each layer, surface and interfacial roughness, etc., can be obtained. In Fig. 3, we displayed the X-ray grazing angle specular reflectivity curves of the samples (open circles). Based on the formalism given by Parrot [10], we simulated the measured specular reflectivity, shown by solid curves in Fig. 3.

It was found, with the increase of the cap thickness, the surface and interfacial roughness decreases, also evidenced by the variation of bumps in the reflectivity curves. From our simulated results, the shift of the $\mathrm{CoSi}_{2}(400)$ peak position and variation of crystalline quality of the silicide films can be understood as follows: without a $\mathrm{Si}$ cap, a $\mathrm{Si}$ rich Co silicide layer formed on the Si substrate, indicating that there exists a significant atomic interdiffusion between Co layer and $\mathrm{Si}$ substrate, which reasonably results in a rough interface between the silicide layer and substrate. When a $13 \mathrm{~nm} \mathrm{Si}$ cap layer is applied, the composition of $\mathrm{Si}$ rich silicide layer becomes closer to the atomic ratio of $\mathrm{CoSi}_{2}$. As such, the silicide layer becomes more coherent in comparison to the bulk $\mathrm{CoSi}_{2}$ and hence has higher crystalline quality. When the cap layer is thickened up to $300 \AA$, the Si content in the silicide layer is found to further decrease. This indicates a decrease in the atomic interdiffusion between Co layer and Si substrate, in accordance with the decrease of the interface roughness. In this case, the silicide is formed mainly by consuming the amorphous Si cap layer, and so the crystalline quality of the silicide degrades.

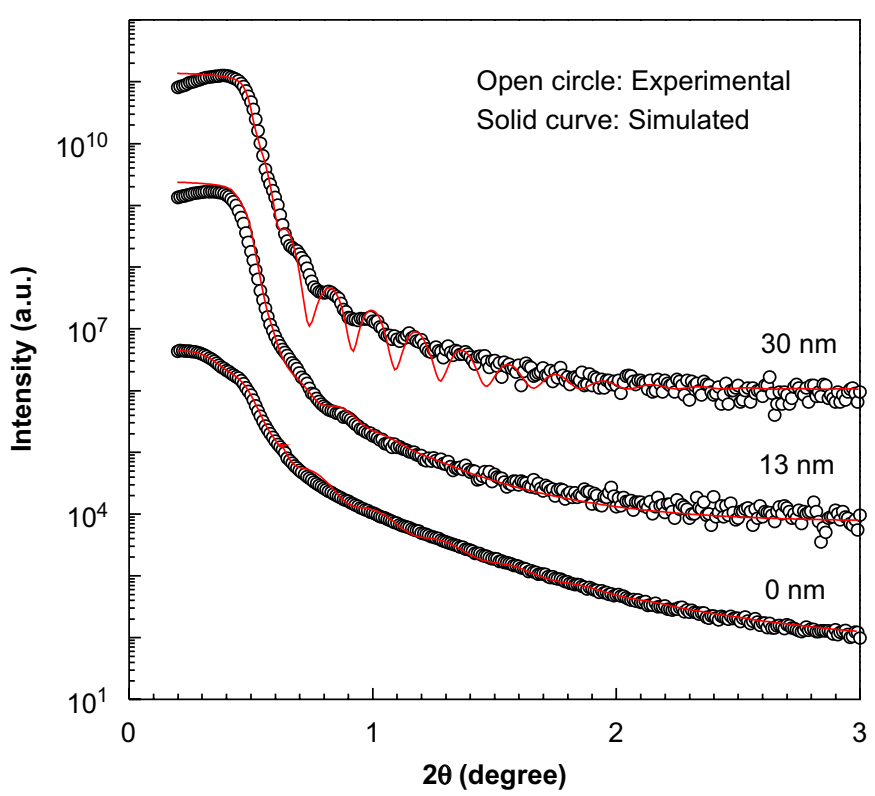

Fig. 3. Specular X-ray reflectivity curves (open circle) and simulated results (solid line) of the $\mathrm{CoSi}_{2}$ films on $\mathrm{Si}(100)$ formed by RTA at $1050^{\circ} \mathrm{C}$ with different $\mathrm{Si}$ cap layer thickness: curve $\mathrm{a}-0 \mathrm{~nm}$; curve $\mathrm{b}-$ $13 \mathrm{~nm}$; curve $\mathrm{c}-30 \mathrm{~nm}$. 
After knowing the optimal $\mathrm{Si}$ cap thickness for the growth of oxide-mediated $\mathrm{CoSi}_{2}$ from this particular thickness of $\mathrm{Co}$, we turn to the further improvement in the crystalline quality of $\mathrm{CoSi}_{2}$ film by introducing moderate Ni content during the deposition of Co layer.

Due to the miscibility of $\mathrm{NiSi}_{2}$ and $\mathrm{CoSi}_{2}$, it has been shown that the formation temperature of $\mathrm{CoSi}_{2}$ can be decreased by introducing $\mathrm{Ni}$ content. On the other hand, since both $\mathrm{NiSi}_{2}$ and $\mathrm{CoSi}_{2}$ have a $\mathrm{CaF}_{2}$-type structure and very close lattice constant $(0.5406$ and $0.5364 \mathrm{~nm}$, respectively), the introduction of $\mathrm{Ni}$ is expected to reduce the stress between $\mathrm{CoSi}_{2}$ and $\mathrm{Si}$ substrate, and hence to improve the crystal quality of $\mathrm{CoSi}_{2}$.

In Fig. 4, we displayed the XRD spectra of $\mathrm{MSi}_{2}$ (M is $\left.\mathrm{Co}_{1-x} \mathrm{Ni}_{x}, x=0-0.385\right)$ after annealing at $1050^{\circ} \mathrm{C}$. To obtain obvious $\mathrm{MSi}_{2}(400)$ peak, $(\theta+\delta)-2 \theta$ scan was still applied. Except for the $\mathrm{CoSi}_{2}$ (400) diffraction peak appearing at $70.73^{\circ}$, we do not observe any other peaks relevant with $\mathrm{CoSi}_{2}$ or $\mathrm{NiSi}_{2}$. It is noted that, the position of $\mathrm{MSi}_{2}(400)$ diffraction peak is almost independent of the $\mathrm{Ni}$ content, indicating that the lattice constant of $\mathrm{MSi}_{2}$ is not affected by the Ni introduction. This is a bit different from the results reported by Mo et al. [11]. In their work, a ternary silicide $\mathrm{Co}_{1-x} \mathrm{Ni}_{x} \mathrm{Si}_{2}$ formed by $\mathrm{Ni}$ and $\mathrm{Co}$ thin films or $\mathrm{Ni}$, Co and $\mathrm{Ti}$ thin films deposited on a $\mathrm{Si}(100)$ substrate was found to have a lattice constant between that of $\mathrm{CoSi}_{2}$ and $\mathrm{NiSi}_{2}$. One possible reason is that, when the $\mathrm{Ni}$ concentration is much lower than that of $\mathrm{Co}$, the lattice of $\mathrm{Co}_{1-x} \mathrm{Ni}_{x} \mathrm{Si}_{2}$ keeps the same as that of $\mathrm{CoSi}_{2}$. The ongoing work on the compositional analysis along the growth direction will possibly give a further interpretation.

The RBS/channeling measurements were performed to check the crystal alignment of $\mathrm{CoSi}_{2}$. The variation of $\chi_{\mathrm{min}}$ with the Ni concentration in displayed in Fig. 5. Shown in the inset in Fig. 5 is the random/channeling RBS spectra of $\mathrm{Co}_{1-x} \mathrm{Ni}_{x} \mathrm{Si}_{2}$ with $x=0.24$ in $\mathrm{Co}_{1-x} \mathrm{Ni}_{x}$. As can be seen

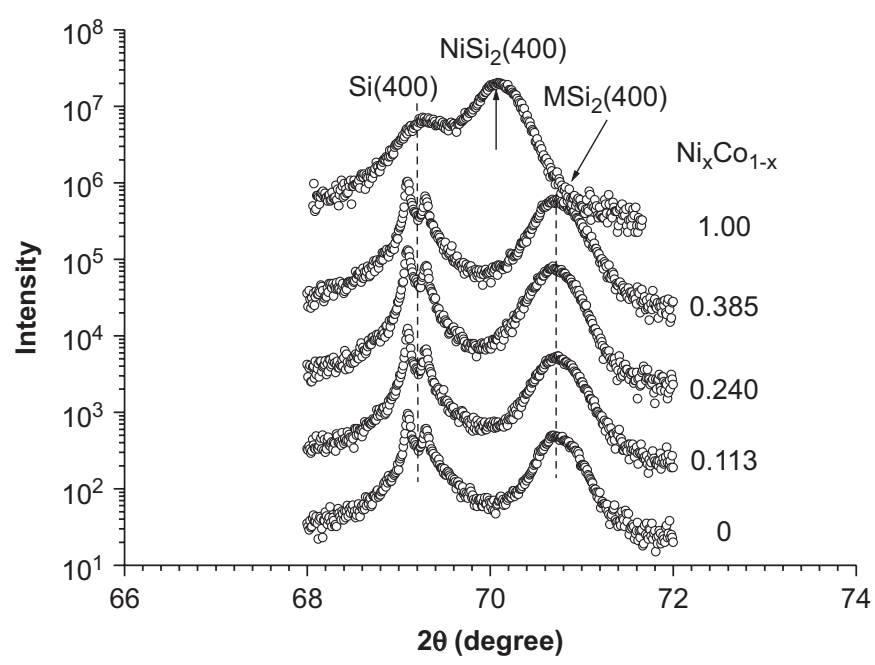

Fig. 4. High-angle X-ray diffraction (HAXRD) spectrum of the oxidemediated $\mathrm{Co}_{1-x} \mathrm{Ni}_{x} \mathrm{Si}_{2}$ films on $\mathrm{Si}(100)$ with different $\mathrm{Ni}$ concentration after annealing at $10500^{\circ} \mathrm{C}$.

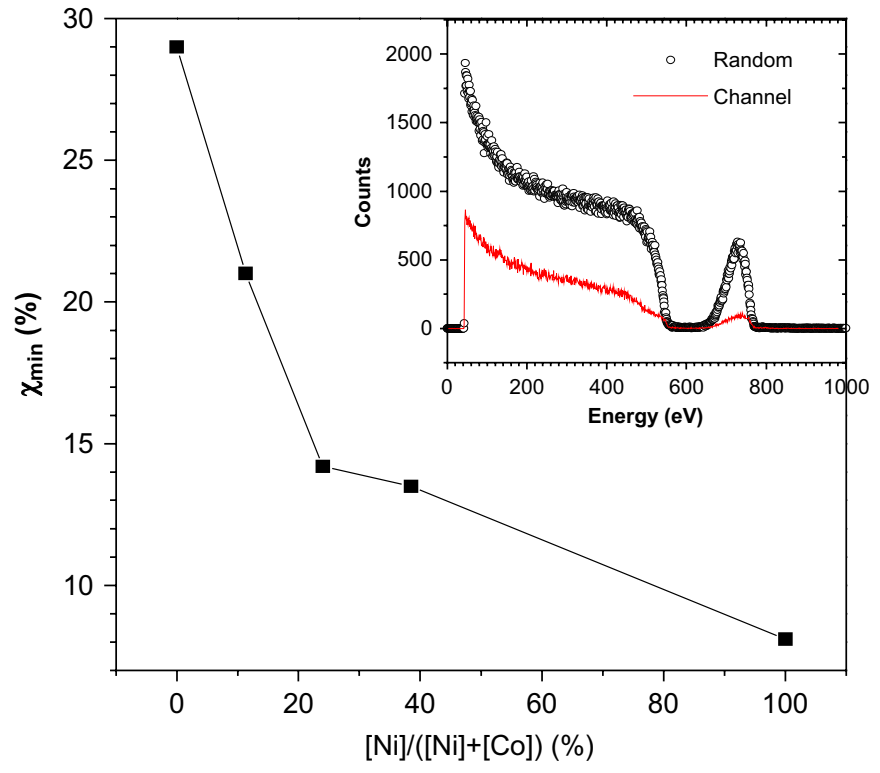

Fig. 5. Variation of $\chi_{\min }$ with $\mathrm{Ni}$ concentration. The inset shows the random/channeling RBS spectra of $\mathrm{Co}_{1-x} \mathrm{Ni}_{x} \mathrm{Si}_{2}$ formed by RTA at $1050{ }^{\circ} \mathrm{C}$ with $x=0.24$ in $\mathrm{Co}_{1-x} \mathrm{Ni}_{x}$.

Table 1

Formation temperature and annealing time of $\mathrm{Co}_{x} \mathrm{Ni}_{1-x} \mathrm{Si}_{2}$ with the best crystallinity

\begin{tabular}{lrcccr}
\hline Ni concentration $(\%)$ & 0 & 11.5 & 24.0 & 38.5 & 100 \\
Temperature $\left({ }^{\circ} \mathrm{C}\right)$ & 1050 & 1050 & 1050 & 1050 & 800 \\
Annealing time (s) & 60 & 60 & 30 & 30 & 60 \\
\hline
\end{tabular}

from Fig. 5, the introduction of $\mathrm{Ni}$ improves the crystal quality, $\chi_{\text {min }}$ decreases with increasing Ni concentration. It was also noted that the temperature and time required for silicide formation was also influenced by the $\mathrm{Ni}$ concentration and is summarized in Table 1. The latter in good agreement with that reported by Park et al. [12] and Detavernier et al. [13]. The decrease of formation temperature or time with increasing $\mathrm{Ni}$ concentration can be attributed to the influence of mixing entropy on the nucleation of $\mathrm{CoSi}_{2}$. The improvement of crystal structure obtained by introducing $\mathrm{Ni}$ is attributed to the reduced diffusion rate of Co into Si substrate. Vantomme et al. [14] explained the growth mechanism of $\mathrm{CoSi}_{2}$ by considering concentration controlled phase selection. It was thought that, in the case of low deposition rate of $\mathrm{Co}$ on $\mathrm{Si}$, the slow supply of Co reduces the effective concentration of Co at the growth interface to a value lower than about 33 at $\%$ $\mathrm{Co}$, so $\mathrm{CoSi}_{2}$ forms directly as the first phase due to the most negative heat of reaction. In our case, the diffusion rate of $\mathrm{Co}$ into $\mathrm{Si}$ substrate is lowered due to the dilution of $\mathrm{Co}$ by $\mathrm{Ni}$ so that the formation of $\mathrm{CoSi}_{2}$ phase is easy. On the other hand, the first formed $\mathrm{Co}_{1-x} \mathrm{Ni}_{x} \mathrm{Si}_{2}$ phase will act as a better template than $\mathrm{CoSi}_{2}$ phase for the following growth of $\mathrm{Co}_{1-x} \mathrm{Ni}_{x} \mathrm{Si}_{2}$ phase. As such, the $\chi_{\text {min }}$ 




Fig. 6. Variation of sheet resistance of $\mathrm{Co}_{1-x} \mathrm{Ni}_{x} \mathrm{Si}_{2}$ film formed by RTA at $1050{ }^{\circ} \mathrm{C}$ with $\mathrm{Ni}$ concentration.

characterizing the crystalline quality of silicide decreases with increasing $\mathrm{Ni}$ concentration.

For the possible application of the $\mathrm{Co}_{1-x} \mathrm{Ni}_{x} \mathrm{Si}_{2}$ films, we measured the sheet resistance of the samples. It was found that, as the Ni concentration increases, the sheet resistance of $\mathrm{Co}_{1-x} \mathrm{Ni}_{x} \mathrm{Si}_{2}$ film first decreased, followed by an increase (Fig. 6). This is possibly due to the formation of a little high-resistance $\mathrm{NiSi}_{2}$ phase (undetectable by XRD) at the surface of $\mathrm{Si}$ substrate as more $\mathrm{Ni}$ is added, since $\mathrm{Ni}$ is easier to diffuse into the Si substrate in comparison to Co. The sheet resistance reaches a minimum $(\sim 5.0 \Omega / \mathrm{sq}$. $)$ as $x=0.115$. In this case, the $\mathrm{Co}_{1-x} \mathrm{Ni}_{x} \mathrm{Si}_{2}$ film thickness is estimated to be round $55 \mathrm{~nm}$. As such, the resistance of the sample with the Ni concentration $x=0.115$ is rather close to the normal value of $\mathrm{CoSi}_{2}$ [15], demonstrating the feasibility of fabricating the applicable $\mathrm{Co}_{1-x} \mathrm{Ni}_{x} \mathrm{Si}_{2}$ film by the simple method mentioned above.

\section{Conclusion}

In a summary, we explored a simple method to grow good-quality $\mathrm{CoSi}_{2}$ by using $\mathrm{Si}$ cap technology and introducing moderate Ni. First, it is revealed that a $13 \mathrm{~nm}$ thick $\mathrm{Si}$ cap layer can significantly improve the crystalline quality of oxide-mediated $\mathrm{CoSi}_{2}$ film formed from a cobalt layer of $\sim 15 \mathrm{~nm}$. Keeping the Si cap thickness at $13 \mathrm{~nm}$, we showed that the introduction of $\mathrm{Ni}$ can further improve the crystal quality of the silicide film in comparison to the pure Co silicide, and a ratio of $\mathrm{Ni}$ to $\mathrm{Co}$ at round 1:8 results in the lowest sheet resistance, $\sim 5 \Omega /$ sq.

\section{Acknowledgments}

This work is supported by IUAP P5/1 GOA (KU Leuven). We thank Mr. B. Opperdoes, Dr. A. Falepin, and Mr. Q. Zhao for their help in MBE experiment, XRD and RBS measurements, respectively.

\section{References}

[1] R.T. Tung, K. Inoue, Inst. Phys. Conf. Ser. 157 (1997) 487.

[2] R.T. Tung, F. Schrey, S.M. Yalisove, Appl. Phys. Lett. 55 (1989) 2005.

[3] R.T. Tung, Appl. Phys. Lett. 68 (1996) 3461.

[4] M.L.A. Dass, D.B. Fraser, C.S. Wei, Appl. Phys. Lett. 58 (1991) 1308.

[5] H. Vanderstraeten, Y. Bruynseraede, M.F. Wu, A. Vantomme, G. Langouche, J.M. Phillips, Appl. Phys. Lett. 57 (1990) 135.

[6] M.F. Wu, J. De Wachter, A.-M. Van Bavel, H. Pattyn, G. Langouche, J. Vanhellemont, H. Bender, K. Temst, B. Wuyts, Y. Bruynseraede, J. Appl. Phys. 75 (1994) 1201.

[7] R.T. Tung, F. Hellman, J.M. Gibson, T. Boone, Mater. Res. Soc. Symp. Proc. 91 (1987) 451.

[8] A. Vantomme, S. Degroote, J. Dekoster, G. Langouche, Appl. Surf. Sci. 91 (1995) 24.

[9] D.K. Sarkar, I. Rau, M. Falke, H. Giesler, S. Teichert, G. Beddies, H.-J. Hinneberg, Appl. Phys. Lett. 78 (2001) 3604.

[10] L.G. Parrot, Phys. Rev. 95 (1954) 359.

[11] H.X. Mo, X.P. Qu, J.H. Liu, G.P. Ru, B.Z. Li, in: Proceedings of the 5th International Conference on Solid State and Integrated Circuit Technology, Category No. 98EX105, 1998, p. 271.

[12] S.J. Park, J.H. Huh, H. Jeon, in: MRS Spring Meeting, San Francisco, CA, 2000

[13] C. Detavernier, R.L. Van Meirhaeghe, F. Cardon, K. Maex, Phys. Rev. B 62 (2000) 12045.

[14] A. Vantomme, S. Degroote, J. Dekoster, G. Langouche, R. Pretorius, Appl. Phys. Lett. 74 (1999) 3137.

[15] K. Maex, Mater. Sci. Eng. R 11 (1993) 53. 